\title{
Effect of Surface Quality of Brass Coating Wire on Wire EDM Characteristics"
}

\author{
Akira OKADA $^{* *}$, Toshiyuki YAMAUCHI ${ }^{* * *}$, Kimihiko ARIZONO ${ }^{* *}$ \\ and Yoshiyuki UNO ${ }^{* *}$ \\ **Okayama University, \\ 3-1-1, Tsushimanaka, Okayama, 700-8530, Japan \\ E-mail: okada@mech.okayama-u.ac.jp \\ ***Tokusen Kogyo Co., Ltd., \\ 1081, Sumiyoshi minamiyama, Ono, Hyogo, 675-1361, Japan \\ E-mail: yamauchi-toshiyuki@tokusen.co.jp
}

\begin{abstract}
The purpose of this study is to develop a new type of wire electrode, in which piano wire with very high tensile strength is coated with electrically conductive layer, such as brass or zinc, in order to attain high speed and high precision wire EDM. In this report, using a trial-made thin wire of $50 \mu \mathrm{m}$ in diameter, the optimum thickness and quality of brass layer were experimentally investigated for higher performance fine wire EDM. Furthermore, the influence of the tensile strength of piano wire used as a core wire was discussed. As a result, the coated brass with copper content of $60-70 \%$ is effective and the thickness of coated brass is needed to be more than $1.45 \mu \mathrm{m}$ for high removal rate.
\end{abstract}

Key words: Wire EDM, Coating Wire, Tensile Strength, Removal Rate, Brass

\section{Introduction}

In wire electrical discharge machining (wire EDM), tungsten wire has been generally used when fine precise machining with thin wire is needed, because higher tension for reducing the wire vibration can be loaded to the wire during machining. However, tungsten is very expensive, which leads to higher cost of product. The purpose of this study is to develop a new type of wire electrode, in which a piano wire with very high tensile strength is coated with electrically conductive layer, such as brass or zinc, in order to attain high speed and high precision wire EDM. In the previous study using the wire of $200 \mu \mathrm{m}$ in diameter, the fundamental effects of the thickness of brass and zinc layers on the machining characteristics were already made clear ${ }^{(1)}$. In this report, using a trial-made thin wire of $50 \mu \mathrm{m}$ in diameter, the optimum thickness and quality of brass layer were experimentally investigated for higher performance fine wire EDM. Furthermore, the influence of the tensile strength of piano wire used as a core wire was discussed.

\section{Experimental Method}

The experiments were carried out using a commercial wire electrical discharge machines with linear motor drive (Sodick AP200L and AQ550L). Machining condition was set to a typical 1st cut condition of large electrical discharge energy. Wires of $50 \mu \mathrm{m}$ in diameter are used as an electrode to understand the effects of the coated brass thickness $\mathrm{Tb}$ and the tensile strength Ts. Wires of $200 \mu \mathrm{m}$ in diameter are used as an electrode in order to understand the copper content in coated brass clearly for coating wire. The core wire 
material and the coated one with their thickness are shown in Table 1. The structure of wire is shown in Fig.1. Wire was newly developed for this research, in which brass is coated on high tensile strength steel wire. Metal mold steel SKD11 in JIS specifications is used as a workpiece, whose thickness is $10 \mathrm{~mm}$. The machined shape is shown in Fig.2, and it includes some corner parts. In general, an electrical discharge machining performance often becomes unstable during machining of corner part, which sometimes leads to wire breakage. Therefore, when this shape can be machined without wire breakage, it can be judged to be machinable.

Table 1 Wire electrodes

\begin{tabular}{c|c|c|c|c}
\hline Types of wire & $\begin{array}{c}\text { Wire } \\
\text { diameter } \\
\mathrm{D}[\mu \mathrm{m}]\end{array}$ & $\begin{array}{c}\text { Thickness of } \\
\text { coated brass } \\
\mathrm{Tb}[\mu \mathrm{m}]\end{array}$ & $\begin{array}{c}\text { Copper content } \\
\text { in coated brass } \\
{[\%]}\end{array}$ & $\begin{array}{c}\text { Tensile } \\
\text { strength } \\
\text { Ts [MPa] }\end{array}$ \\
\hline TKC & 200 & 10.00 & $0-100$ & - \\
\hline TKC-Normal & 50 & $0.67-2.80$ & 71 & 3138 \\
\hline TKC-LowTs & 50 & 1.70 & 73 & 2195 \\
\hline Wire-A & 50 & 3.00 & 66 & 2225 \\
\hline Tungsten & 50 & - & - & 3411 \\
\hline
\end{tabular}

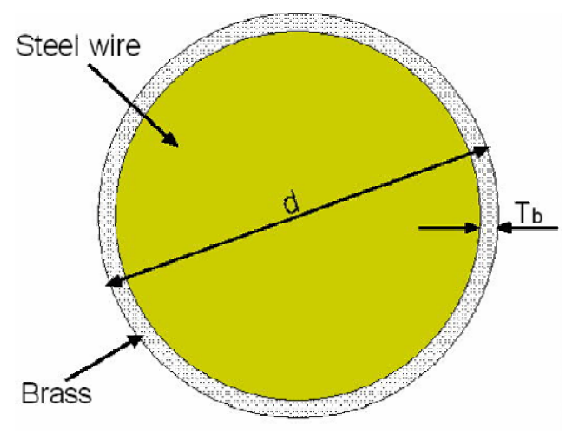

Fig. 1 Structure of coating wires

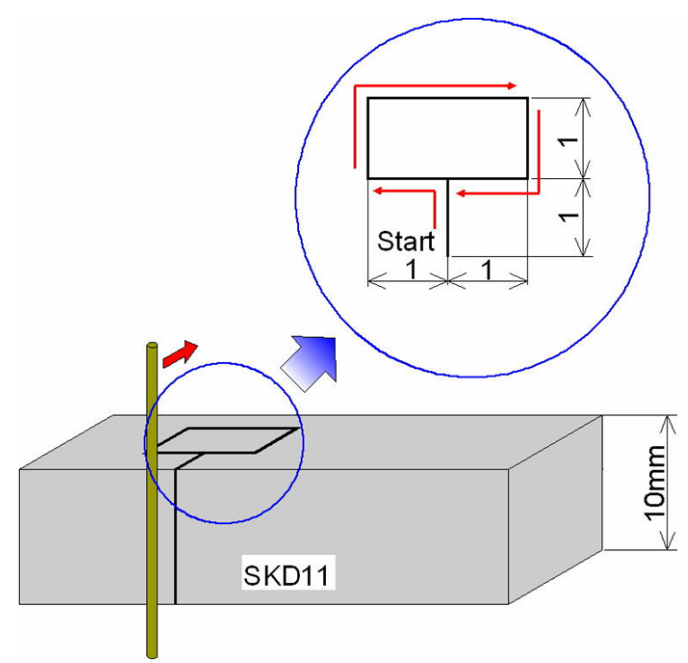

Fig. 2 Machining shape

\section{Results and Discussion}

\subsection{Effects of copper content in coated brass}

It was well known that the electrical conductivity of wire electrode is very important 
factor in wire EDM process, because it affects electrical discharge current peak value, the time required to reach the peak current, and consequently the machining characteristics, such as removal rate and surface finish. Therefore, the influence of the copper content in coated brass on removal rate was investigated at first. The relation between the removal rate and the copper content in coated brass is shown in Fig.3. As can be seen from the figure, when the copper content in coated brass is $0 \%$, the removal rate is a little smaller than that using conventional brass wire. This is because the electric conductivity of zinc is low, compared with brass. The removal rate increases with copper content in coated brass. When the copper content is over $70 \%$ the removal rate decreases. And when the copper content is $100 \%$, the removal rate becomes about $40 \%$ of that using the brass wire. It was reported that zinc has an effect to disperse the occurrences of electrical discharge ${ }^{(1)}$. Therefore, when the copper content is $100 \%$, it is easy to concentrate the electrical discharges because of no zinc. Consequently, the machining became unstable and the removal rate decreased. The direct reasons causing the variation of removal rate shown here are considered to be changes in machined kerf width, pulse frequency of electrical discharge, and electrical discharge current value. That is, the removal rate generally becomes high as the kerf width is small, the pulse frequency is high, and the discharge current value is large. Each factor is discussed in the following.

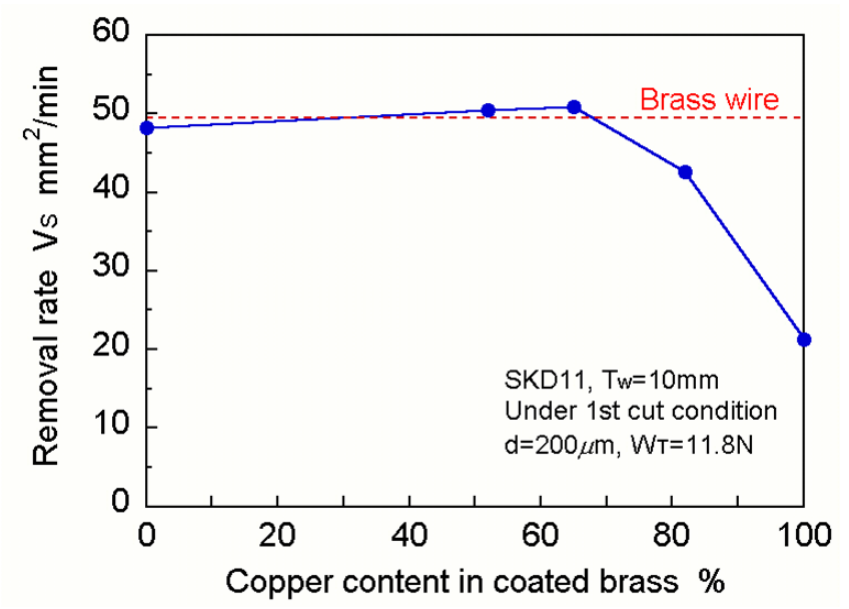

Fig. 3 Relationship between removal rate and composition of coated brass

\section{(1) Kerf width}

After machining a slit of about $10 \mathrm{~mm}$ in length, the machined kerf width was measured. There were not any differences between the coating wires and the conventional brass wire.

(2) Discharge current

The electrical discharge current peaks were investigated. Under the 1 st cut condition, 20,000 times or more electrical discharges take place between the gap in every second during machining, and all discharge waveforms are not the same. Therefore, 100 or more current waveforms were recorded at random by using high response digital oscilloscope to obtain the distribution of the current peak value. The distributions of discharge current with copper content in coated brass are shown in Fig.4. In the case of conventional brass wire, the probability of discharges of about $295 \mathrm{~A}$ is the highest, the average discharge current is also about $295 \mathrm{~A}$, and there is about $\pm 10 \mathrm{~A}$ variation. On the other hand, the average current values in the cases of coated wire are smaller than those using conventional brass wire. And the average current value increases with copper content. Furthermore, when the copper content in coated brass is $0 \%$, the current peak value is smaller than any other copper 
contents. This is because the electric conductivity of zinc is smaller than that of copper. From these results, when copper content in coated brass is small, the electric conductivity of the wire decreases and the electrical discharge current peak value also decreases. As a result, the removal rate decreased in this case.

(3) Pulse frequency

Pulse frequency of electrical discharges was measured by using the pulse counter. Figure 5 shows the relationship between pulse frequency of electrical discharges and copper content in coated brass. As shown in the figure, when copper content in coated brass is less than $80 \%$, the pulse frequency using the brass coated wire is slightly higher than that using conventional brass wire. The pulse frequency values using the brass coated wire are almost the same at this time. However, when the copper content in coated brass is close to $100 \%$, the pulse frequency becomes small. When the copper content in coated brass is too high, the electrical discharge concentration is easy to happen, which leads to small pulse frequency and low removal rate as mentioned above. From these results, the copper content in coated brass should be adjusted to $60-70 \%$ in order to attain the high removal rate.

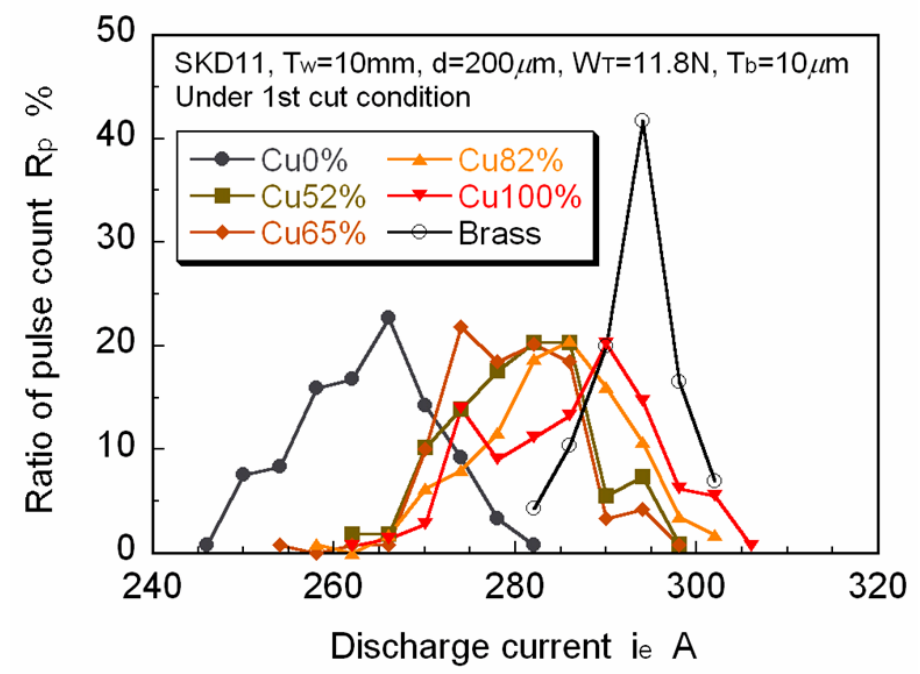

Fig. 4 Distributions of discharge current for various compositions of coated brass

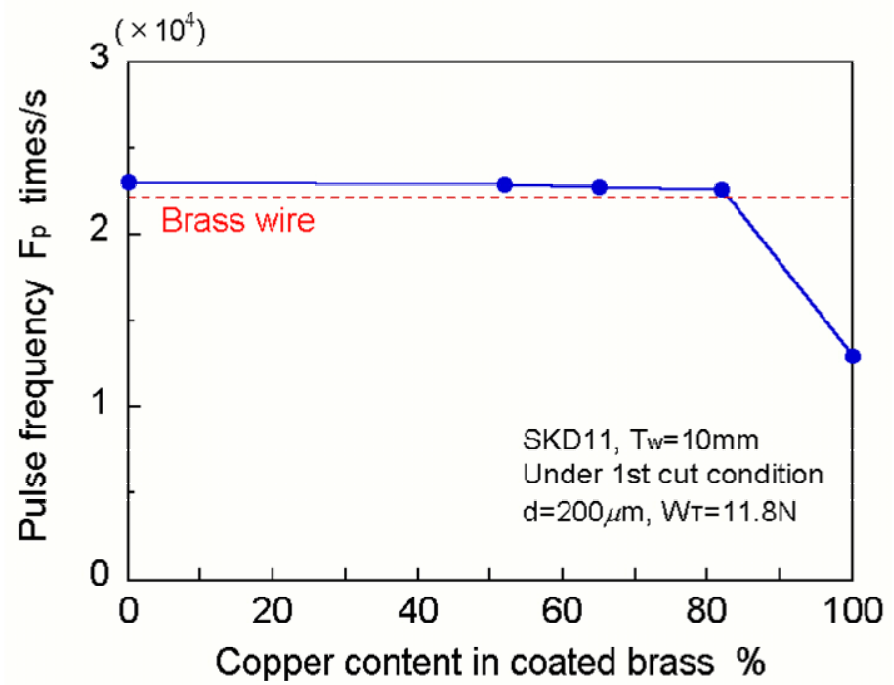

Fig. 5 Relationship between pulse frequency and composition of coated brass 


\subsection{Effects of coated brass thickness}

Next, the influence of coated brass thickness on the removal rate was investigated. Figure 6 shows the relationship between removal rate and thickness of coated brass. The removal rate becomes larger with an increase of coated brass thickness. However, when the thickness of coated brass is more than $1.45 \mu \mathrm{m}$, the removal rate doesn't increase very much. Therefore, it is thought that the coated brass thickness of $1.45 \mu \mathrm{m}$ is necessary to obtain high removal rate. In order to investigate this cause, kerf width, pulse frequency of electrical discharge, and electrical discharge current value were examined. As a result, neither the electrical discharge current value nor the kerf width had the effect on the removal rate.

The relationship between pulse frequency of electrical discharge and thickness of coated brass is shown in Fig.7. As can be seen from the figure, the pulse frequency of electrical discharges becomes larger with thickness of coated brass. This tendency well corresponds well to that of removal rate, and it is supposed that one of the factors increasing the removal rate is the increase of pulse frequency with thickness of coated brass.

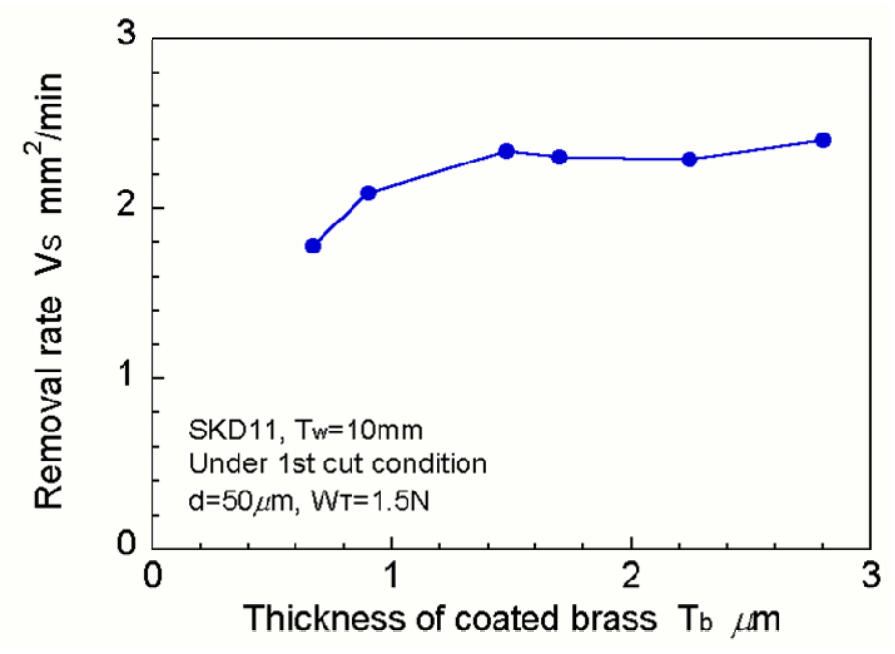

Fig. 6 Relationship between removal rate and thickness of coated brass

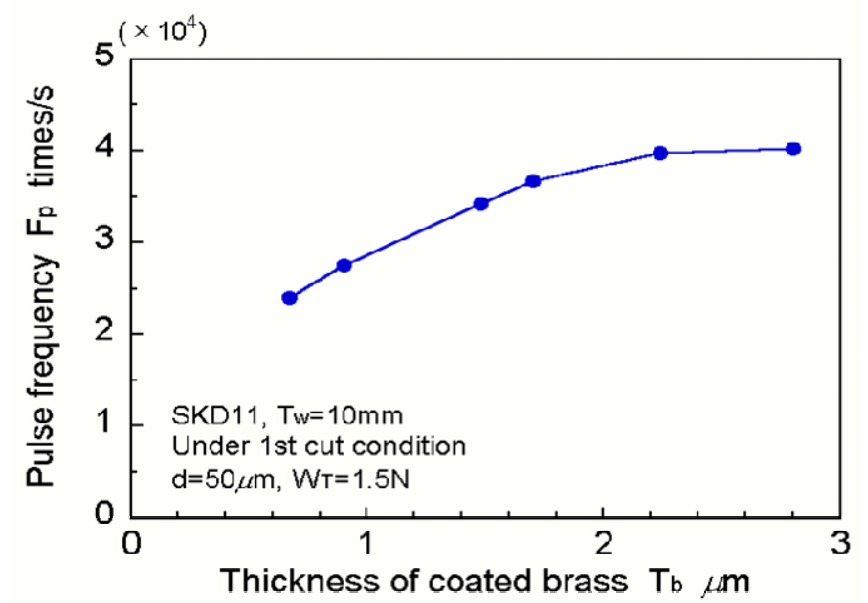

Fig. 7 Relationship between pulse frequency and thickness of coated brass

In addition, the adhesion of coating material is investigated in order to understand the optimum thickness of coated brass layer. Figure 8 shows the quantitative analysis of machined surface with thickness of coated brass. When the thickness of coated brass is 
small, the ratio of copper and zinc adhering to machined surface becomes a little larger with an increase of thickness of coated brass. However, the ratio hardly changes in the case of thick brass layer, since thickness of $1.45 \mu \mathrm{m}$ is sufficiently large to generate the discharges. This tendency corresponds well to the variation of the removal rate with coated brass thickness. That is, when the thickness of coated brass is more than $1.45 \mu \mathrm{m}$, the coated brass layer remains on the wire during wire EDM, and high electric conductivity of the wire can be kept. Therefore, stable machining can be realized and high removal rate can be attained. From these results, the thickness of coated brass of about $1.45 \mu \mathrm{m}$ is necessary to obtain the high removal rate.

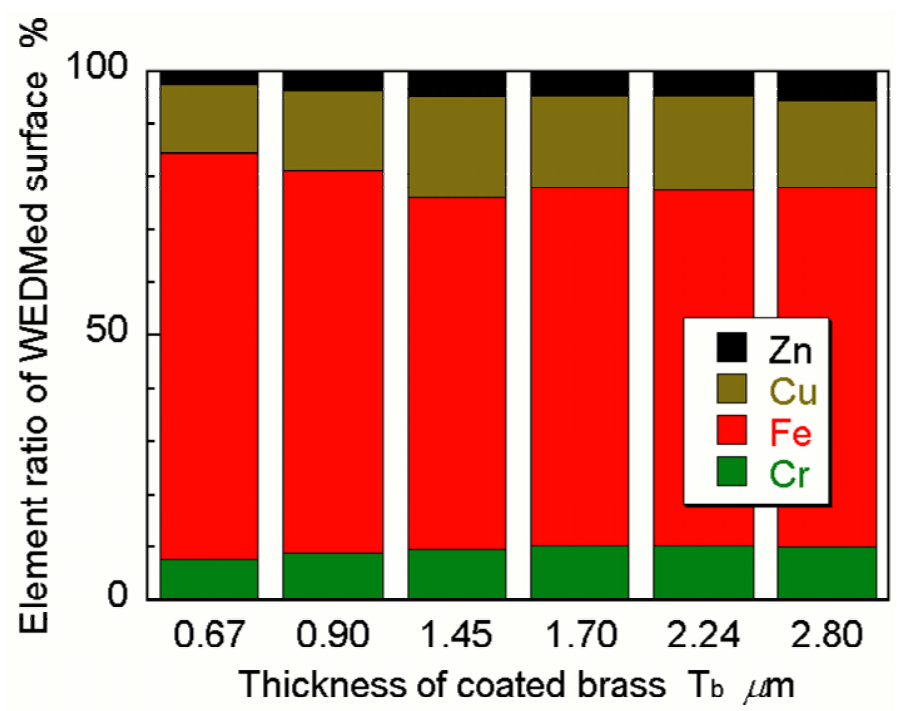

Fig. 8 Quantitative analysis of machined surface by EDX

\subsection{Effects of wire tension}

In general, the wire is vibrating during wire EDM. The wire vibration causes large kerf width. Consequently, the removal rate becomes small because the machining volume increases ${ }^{(2)}$. In order to minimize the wire vibration, high wire tension is effective. Then, the removal rate was measured for each wire under the proper conditions, increasing the wire tension until wire breakage.

Figure 9 shows the variation of removal rate with the wire tension. As shown in the figure, the removal rate becomes larger with an increase of wire tension. It is guessed that the kerf width decreases because the wire vibration becomes small, and then the removal rate increases. In the case of the coating wire, the removal rate increases until the wire breakage. On the other hand, in the case of tungsten wire, the removal rate takes a maximum at $3.0 \mathrm{~N}$, and then decreases. In order to investigate this cause, kerf width, pulse frequency of electrical discharge, and electrical discharge current value were examined. As a result, there were no differences in the electrical discharge current value, pulse frequency of electrical discharge.

Figure 10 shows the relation between kerf width and wire tension when the tungsten wire is used. Here, this graph includes the scattering in addition to the average value of kerf width. As the wire tension increases, the average value of kerf width becomes small. However, it can be confirmed that the scattering of kerf width becomes larger from about $3 \mathrm{~N}$ in wire tension. At the same time, the removal rate begins to decrease as shown above. When the wire tension is larger than $3 \mathrm{~N}$, the movement of wire becomes unstable by the local vibration, and the removal rate decreases. In the case of coating wire, the average kerf width decreased with wire tension, and the removal rate increased as shown in Fig.9. The scattering of kerf width using coated wires was almost constant regardless with wire tension, because the wire breakage always occurs before reaching the wire tension in which the scattering of kerf width increases. 


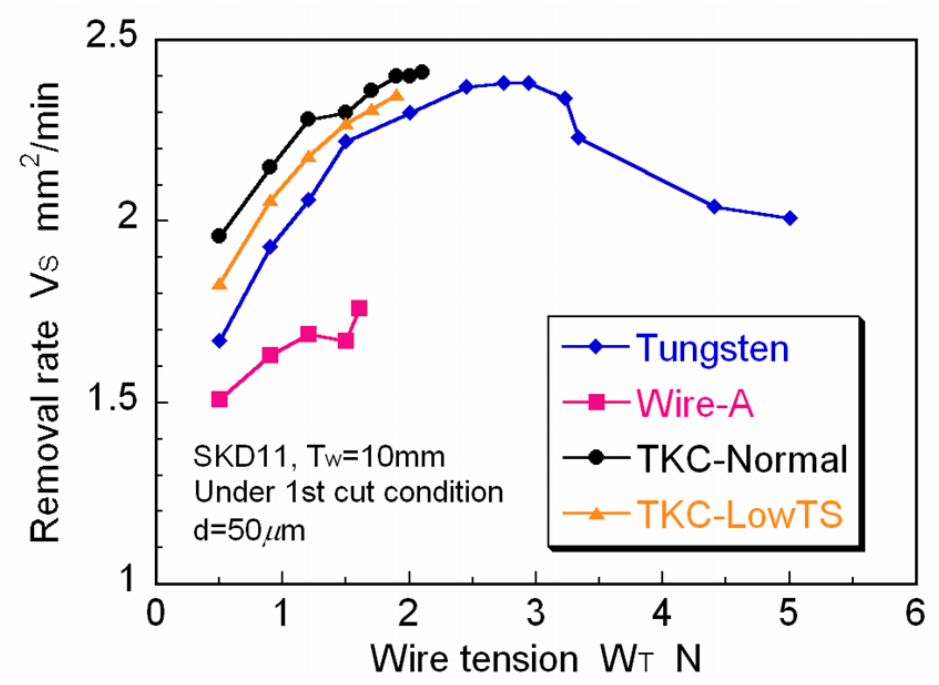

Fig. 9 Relationships between removal rate and wire tension for various kinds of wire

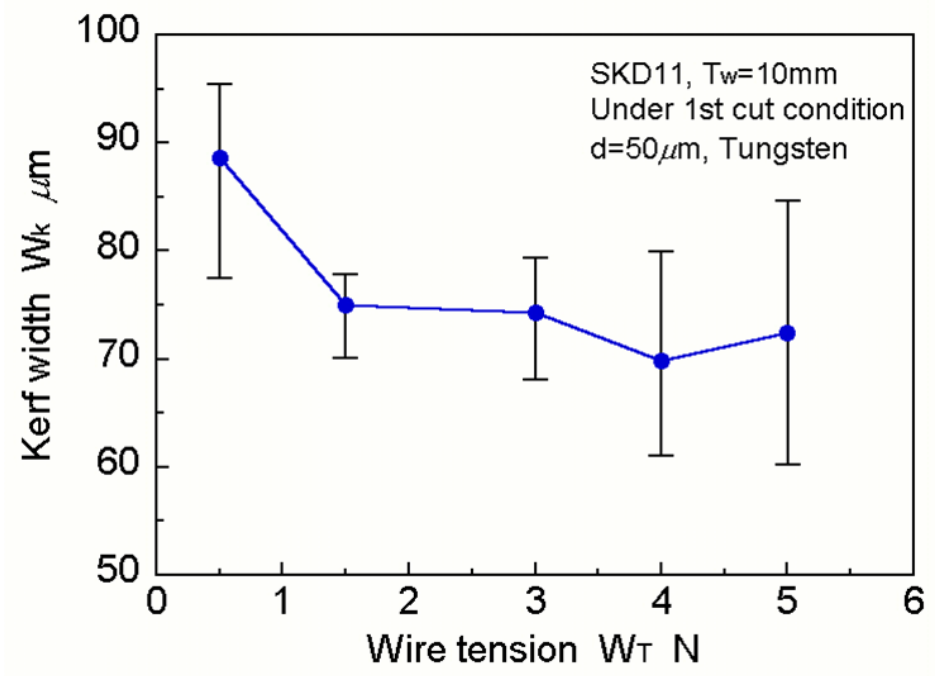

Fig. 10 Relationship between kerf width and wire tension using tungsten wire

\section{Conclusions}

(1) The removal rate takes a maximum when the copper content in the coated brass is about $60-70 \%$.

(2) The thickness of coated brass should be about $1.45 \mu \mathrm{m}$ to obtain a high removal rate in brass coating wire of $50 \mu \mathrm{m}$ in diameter.

(3) The removal rate becomes larger with an increase of wire tension because the vibration can be reduced with wire tension.

(4) In the case of conventional tungsten wire, when the wire tension is too high, the removal rate decreases because of unstable wire vibration.

\section{References}

(1) Morita,M., Yamauchi,T., Okada,A., Uno,Y. and Shimizu,T., Fundamental Study on Coating Wire Electrode for High Performance WEDM, Proceedings of the $3^{\text {rd }}$ International Conference on Leading Edge Manufacturing in $21^{\text {st }}$ Century, (2005), pp.779-782.

(2) Manabe,A. and Haseki,Y., Wire Electrical Discharge Machining (in Japanese), (1997), pp.154-155, Nikkan- Kogyo-Shinbun-Sya. 